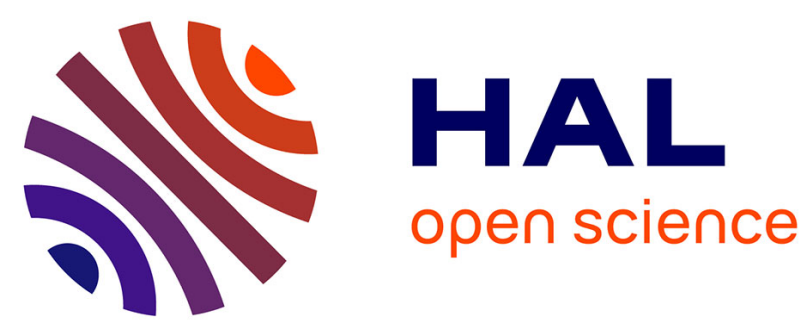

\title{
Screening for polybrominated diphenyl ethers in biological samples by reversed-phase fast HPLC-ICP MS
}

Katarzyna Bierla, A. Riu, L. Debrauwer, Daniel Zalko, Brice Bouyssière, Joanna Szpunar

\section{- To cite this version:}

Katarzyna Bierla, A. Riu, L. Debrauwer, Daniel Zalko, Brice Bouyssière, et al.. Screening for polybrominated diphenyl ethers in biological samples by reversed-phase fast HPLC-ICP MS. Journal of Analytical Atomic Spectrometry, 2010, 25 (6), pp.889-892. 10.1039/c000686f . hal-01529896

\section{HAL Id: hal-01529896 \\ https://hal.science/hal-01529896}

Submitted on 31 May 2020

HAL is a multi-disciplinary open access archive for the deposit and dissemination of scientific research documents, whether they are published or not. The documents may come from teaching and research institutions in France or abroad, or from public or private research centers.
L'archive ouverte pluridisciplinaire HAL, est destinée au dépôt et à la diffusion de documents scientifiques de niveau recherche, publiés ou non, émanant des établissements d'enseignement et de recherche français ou étrangers, des laboratoires publics ou privés. 


\title{
Screening for polybrominated diphenyl ethers in biological samples by reversed-phase fast HPLC-ICP MS
}

\author{
Katarzyna Bierła, ${ }^{a}$ Anne Riu, ${ }^{b}$ Laurent Debrauwer, ${ }^{b}$ Daniel Zalko, ${ }^{b}$ Brice Bouyssiere $^{a}$ and Joanna Szpunar ${ }^{a}$ \\ Received 12th January 2010, Accepted 26th February 2010 \\ First published as an Advance Article on the web 24th March 2010 \\ DOI: 10.1039/c000686f
}

The coupling of fast (ultrahigh pressure) liquid chromatography with ICP MS fitted with an octopole collision cell was developed for the separation and detection of ten polybrominated diphenyl ethers (PBDE) (47, 85, 100, 138, 155, 201, 206, 207, 208, 209). The compounds were eluted within 12 min using an acetonitrile-rich (70-95\%) mobile phase at $1.5 \mathrm{~mL} \mathrm{~min}^{-1}$ which could be introduced directly into an inductively coupled plasma owing to a new plasma frequency-marching RF generator. The limit of detection (as bromine) at these conditions was $17 \pm 1 \mathrm{ng} \mathrm{mL}^{-1}$ and was independent of the mobile phase composition. The method was applied to the screening metabolites of the high molecular weight PBDE decabromodiphenyl ether in rat liver and faeces and was validated by independent HPLC with radioactivity detection. It offered, as a main advantage over molecular MS, the virtual independence of the signal intensity of the molecular structure of the compound, and thus the possibility to detect unknown metabolites and control bromine mass balance.

\section{Introduction}

The determination of polybrominated diphenyl ethers, a class of synthetic organic compounds used as flame retardants, is becoming of increasing concern because of their persistence in the environment, bioaccumulation, and potential toxicity. ${ }^{1}$ There can exist 209 different PBDE congeners, varying in number and position of bromination but many of them are unstable and tend to debrominate in the environment. ${ }^{2}$ The most frequently used, and one of the most persistent, is decabromodiphenyl ether (bis(pentabromophenyl) ether; BDE-209 in Fig. 1) which accounted (in the mid 1990's) for 75\% of PBDE flame retardants used in the EU. ${ }^{3}$ Being lipophilic, PBDEs have a tendency to accumulate in fatty tissues but also in target endocrine glands such as the adrenals, and magnify up the food chain. ${ }^{4-6}$ The congener composition varies in different biological specimens because of the different breakdown pathways. ${ }^{7}$ Studies of the metabolism of PBDEs depend critically on the availability of analytical methods allowing the separation of the different congeners, and their detection, identification, and quantitative determination.

Gas chromatography (GC), used routinely with electron impact ionization high resolution mass spectrometric detection for the analysis of low molecular mass (up to $c a$. 700) PBDEs, ${ }^{\mathbf{4}, \mathbf{8}, 9}$ fails for heavier congeners because of the long retention times and on-column degradation. ${ }^{10}$ Therefore, HPLC has recently been proposed as the alternative. ${ }^{6,11-13}$ The separation, carried out by reversed-phase HPLC, requires high contents of organic modifiers for quantitative elution of the PBDEs ${ }^{10}$ and reliable and straightforward detection techniques are lacking. As PBDEs are difficult to ionize efficiently by electrospray or chemical

${ }^{a}$ CNRS/UPPA, LCABIE, UMR 5254, Hélioparc, 2, Avenue Angot, 64053 Pau, France

${ }^{b}$ INRA, UMR 1089 Xénobiotiques, 180 Chemin de Tournefeuille, 31027 Toulouse cedex 3, France ionization, atmospheric pressure photoionization (APPI) is required for molecular MS detection. ${ }^{11,12,13}$ The fragmentation patterns being similar for many compounds, the development of complex detection schemes based on the multiple reaction monitoring is necessary for each analyte in APPI MS/MS. ${ }^{11,12}$

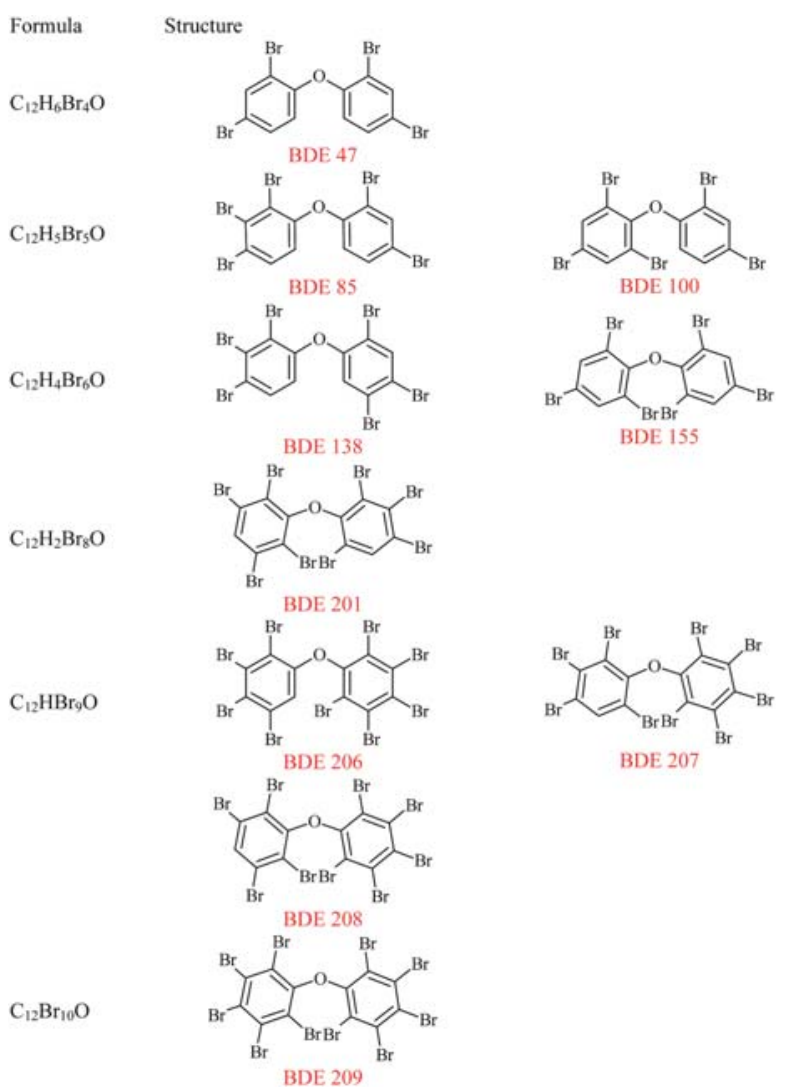

Fig. 1 Structures of the studied compounds. 
The a priori knowledge of the metabolites is necessary, their ionization differing from one compound to the other and being dependent on the chromatographic conditions. An alternative is the use of ${ }^{14} \mathrm{C}$-labelled PBDE species which could be detected in HPLC on the basis of their radioactivity. ${ }^{6,14}$ The use of radioactive compounds is limited to model experiments and requires dedicated synthesis of the target molecules.

Inductively coupled plasma mass spectrometry (ICP MS) is a convenient detector of heteroatom-bearing compounds in HPLC $^{15,16}$ because of its sensitivity and the response being virtually independent of the molecular structure of the compound and readily controlled in different mobile phase conditions. The detection of bromine by ICP MS is, however, negatively affected not only by its relatively high 1st ionization potential $(11.84 \mathrm{eV})^{17}$ and the low degree of ionization in the plasma $(\mathrm{ca} .5 \%)^{18}$ but also by the common polyatomic interferences: ${ }^{38} \mathrm{Ar}^{40} \mathrm{Ar}^{1} \mathrm{H}^{+}$and ${ }^{40} \mathrm{Ar}^{40} \mathrm{Ar}^{1} \mathrm{H}^{+}$on the both bromine isotopes: ${ }^{79} \mathrm{Br}(50.69 \%)$ and ${ }^{81} \mathrm{Br}(49.31 \%)$, respectively. Nevertheless, ICP MS detection of bromine was successfully used in GC of bacterial breakdown products of PBDEs ${ }^{19}$ and pesticides ${ }^{20}$ and in HPLC of ${ }^{3} \mathrm{H}$-bromohexine, ${ }^{21}$ 4-bromoaniline metabolites, ${ }^{22}$ and bromine containing preservatives in cosmetic products. ${ }^{17}$

The goal of this work was the development of a HPLC-ICP MS method for a rapid screening of the metabolites of decabromodiphenyl ether in rat liver and faeces. The removal of polyatomic interferences was achieved by the use of a collision cell. A new plasma frequency-marching RF generator was examined to cope with the high-flow rates of organics-rich phases used, necessary for the elution of PBDE compounds in fast HPLC.

\section{Experimental}

\section{Instrumentation}

Chromatographic separations were carried out using a 1200 Model rapid resolution LC (Agilent, Wilmington, DE) as the delivery system. The ICP mass spectrometer was an Agilent 7700 (Tokyo, Japan) equipped with a plasma frequency-matching RF generator and an octopole reaction collision cell. The exit of the column (Agilent ZORBAX Eclipse XDB-C18: $4.6 \times 50 \mathrm{~mm}$, $1.8 \mu \mathrm{m}$ ) was connected by means of PEEK tubing to the Meinhard nebulizer (Glass Expansion, Romainmotier, Switzerland) fitted with a Peltier-cooled double-pass quartz spray chamber (Glass Expansion) A 1-mm id injector torch and platinum sampler and skimmer cones were used. Samples were injected by means of a Rheodyne valve with a $100 \mu \mathrm{L}$ sample loop. Samples were filtered prior to analysis by centrifugation (Ependorff, Le Pecq, France) using 0.2- $\mu \mathrm{m}$ filters (VWR International, Fontenay-sous-Bois, France). A microbore column SB-C18 (Agilent, Zorbax: $150 \times 0.5 \mathrm{~mm}, 5 \mu \mathrm{m})$ and an Agilent Model 7500ce ICP MS (Tokyo, Japan) were used in the initial phase of the study.

\section{Reagents, solutions and materials}

Analytical reagent grade chemicals, purchased from SigmaAldrich (Saint-Quentin Fallavier, France), and water (18 M $\Omega$ $\mathrm{cm}$ ) obtained with a Milli-Q system (Millipore, Bedford, MA), were used throughout unless stated otherwise. The chromatographic mobile phases were degassed by purging with helium. The PBDE standards were obtained as $50 \mu \mathrm{g} \mathrm{mL}^{-1}$ stock solution in nonane or nonane/toluene from Wellington Laboratories (Guelph, ON, Canada) with the exception of BDE-209 purchased from Sigma-Aldrich. Their empiric formulas and structures are given in Fig. 1. The stock solutions were evaporated to dryness, re-dissolved in toluene and diluted with acetonitrile to reach the nominal concentration.

\section{Metabolic experiments}

Metabolic experiments were carried out as described in detail elsewhere. ${ }^{6}$ In brief, three pregnant Wistar rats were purchased from Charles River (l'Arbresle, France) and housed individually in stainless metabolic cages. Animals were allowed free access to water and standard diet (SAFE, Augy, France). They were maintained on a 12-h light/dark cycle. Each animal was force-fed daily with decabromodiphenyl ether solubilised in peanut oil from gestational days 16 to 19 . Faeces were collected daily over 4-day period. Animals were killed by cervical dislocation followed by exsanguination on the 20th day of gestation. The liver of each animal was removed and stored at $-20{ }^{\circ} \mathrm{C}$ until analysis.

\section{Sample preparation}

Liver and faeces were homogenised and aliquots ( $c a .1 \mathrm{~g})$ were taken for analysis. PBDEs were extracted as described elsewhere. ${ }^{6}$ In brief, each sample aliquot was extracted three times with fresh 5-mL (liver) or 10-mL (faeces) portions of acetonitrile and then three more times with similar portions of acetonitriletoluene mixture $(90: 10, \mathrm{v} / \mathrm{v})$. The extracts were combined, evaporated to dryness under $\mathrm{N}_{2}$ and the residue was re-dissolved in $1.5 \mathrm{~mL}$ of toluene.

\section{Procedure}

A $10-\mu \mathrm{L}$ sample aliquot was chromatographed for $12 \mathrm{~min}$ using a gradient of water (A) and acetonitrile (B) according to the following programme: $0-4 \mathrm{~min}(70 \% \mathrm{~B}), 4-8.5 \mathrm{~min}(90 \% \mathrm{~B})$, $8.5-11.5 \mathrm{~min}(95 \% \mathrm{~B})$ and $11.5-12 \mathrm{~min}(70 \% \mathrm{~B})$ at a flow rate of $1.5 \mathrm{~mL} \mathrm{~min}{ }^{-1}$. The isotopes monitored were ${ }^{79} \mathrm{Br}$ and ${ }^{81} \mathrm{Br}$ (dwell time $0.1 \mathrm{~s}$ ). Flow rates of collision gas (helium) and carrier gas (argon) were optimized to obtain the correct ${ }^{79} \mathrm{Br} /{ }^{81} \mathrm{Br}$ isotopic ratio and to maximize the sensitivity, respectively. The optimum values were $2 \mathrm{~mL} \mathrm{~min}^{-1}$ for the helium collision gas and $0.65 \mathrm{~L}$ $\min ^{-1}$ for the argon carrier gas. The plasma RF power was 1550 W. $8 \%$ of oxygen was added to the argon carrier gas. Spray chamber temperature was maintained at $-5{ }^{\circ} \mathrm{C}$.

\section{Results and discussion}

\section{Optimisation of HPLC-ICP MS analysis PBDEs}

The reversed-phase HPLC separations of PBDEs are known to require high concentrations of organic modifier (e.g. $90 \%$ methanol) $)^{6,11-13}$ which cannot be readily tolerated at $1 \mathrm{~mL} \mathrm{~min}^{-1}$ by the model 7500 Agilent ICP MS. Therefore, microbore HPLC separation at $50 \mu \mathrm{L} \mathrm{min}{ }^{-1}$ using a dedicated interface described elsewhere ${ }^{23}$ was optimized. The system allowed a stable detection of bromine but the sensitivity in $90 \%$ methanol was one order of 
magnitude lower than in aqueous solutions and the baseline separation of the pairs of PBDE congeners 85/100 and 207/208 could not be obtained.

In a second attempt, ultra-high performance HPLC using $1.8-\mu \mathrm{m}$ beads was examined in order to improve the separation efficiency. UPLC-ICP MS was first proposed to speciation analysis (of Se compounds) by Bendahl et $a .^{24}$ It was then applied by the same group to investigate bromine speciation in cosmetic products with a lot of problems due to the high solvent load despite the relatively low flow rates $\left(90 \mu \mathrm{L} \mathrm{min}{ }^{-1}\right)$ and methanol concentrations (up to $40 \%$ ) used. ${ }^{17}$ Our optimization efforts have resulted in the baseline separation of all the PBDEs investigated except the pair of PBDE congeners 207/208 which have the same molecular mass and vary only slightly in the structure ( $c f$. Fig. 1). As no data suggesting any differences in the metabolism and toxicology of these two isomers are available, the separation obtained was considered to be satisfactory.

This satisfactory separation could, however, be obtained using

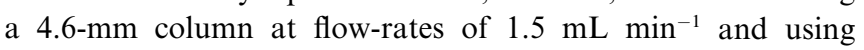
a mobile phase containing more than $70 \%$ of acetonitrile during most of the duration of the run. In these conditions the plasma could not be sustained. Therefore, the tolerance to such solutions of a new generation ICP MS spectrometer (Agilent 7700), equipped with the fast frequency-matching RF generator, was investigated. Using a standard sample introduction system (Meinhard nebulizers) and double-pass Scott spray chamber
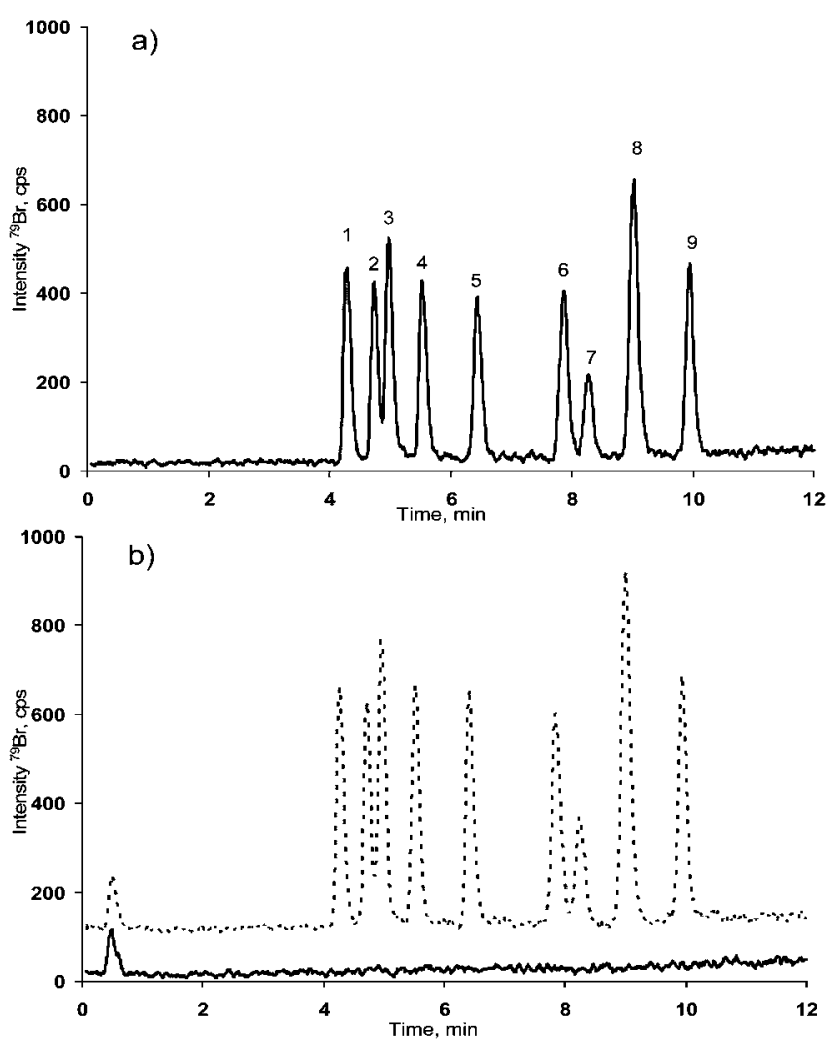

Fig. 2 HPLC-ICP MS chromatograms of (a) standards; (1) BDE 47, (2) BDE 85, (3) BDE 100, (4) BDE 138, (5) BDE 155, (6) BDE 201, (7) BDE 206, (8) BDE 207 and 208, (9) BDE 209, $0.25 \mu \mathrm{g} \mathrm{mL}^{-1}$ of each (b) -: control liver sample; ---: control liver sample spiked with the mixture of $0.4 \mu \mathrm{g} \mathrm{mL}^{-1}$ as in Fig. 2a. cooled down to $-5^{\circ} \mathrm{C}$, acetonitrile could be fed directly in to the

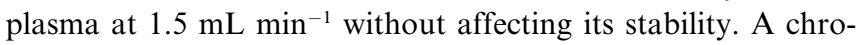
matogram obtained in these conditions for the mixture of PBDE standards is shown in Fig. 2a. It is not affected by the sample matrix as demonstrated in Fig. 2 b.

\section{Analytical figures of merit}

The effect of the acetonitrile concentration on the sensitivity was examined by comparing the slopes of the calibration curves obtained for a FIA-ICP MS analysis of $\mathrm{NaBr}$ solution using the mobile phases containing $0,35,70,80$ and $95 \% \mathrm{v} / \mathrm{v}$ acetonitrile. The limits of detection calculated as blank $+3 \sigma$ were: $4,16,18$, 18 and $16 \mathrm{ng} \mathrm{mL}^{-1}$, respectively. It can be seen that although the organic modifier reduced the sensitivity by a factor of 4 , this decrease happened between 0 and $35 \%$ fraction of acetonitrile. Consequently, the sensitivity remained constant at acetonitrile concentrations exceeding $35 \%$ which largely facilitated quantification. Note that the behaviour of the 7700 series generator used in this work is different from that of the 7500 series. Indeed, when the latter was used, a tremendous drop in sensitivity due to the presence of high concentrations of an organic modifier was observed ${ }^{25}$ and needed to be compensated for by dedicated setups or calibration strategies.

As all the investigated compounds elute at acetonitrile concentrations above $35 \%$, no trend in the decrease of the detection limits was observed. They were on the level of
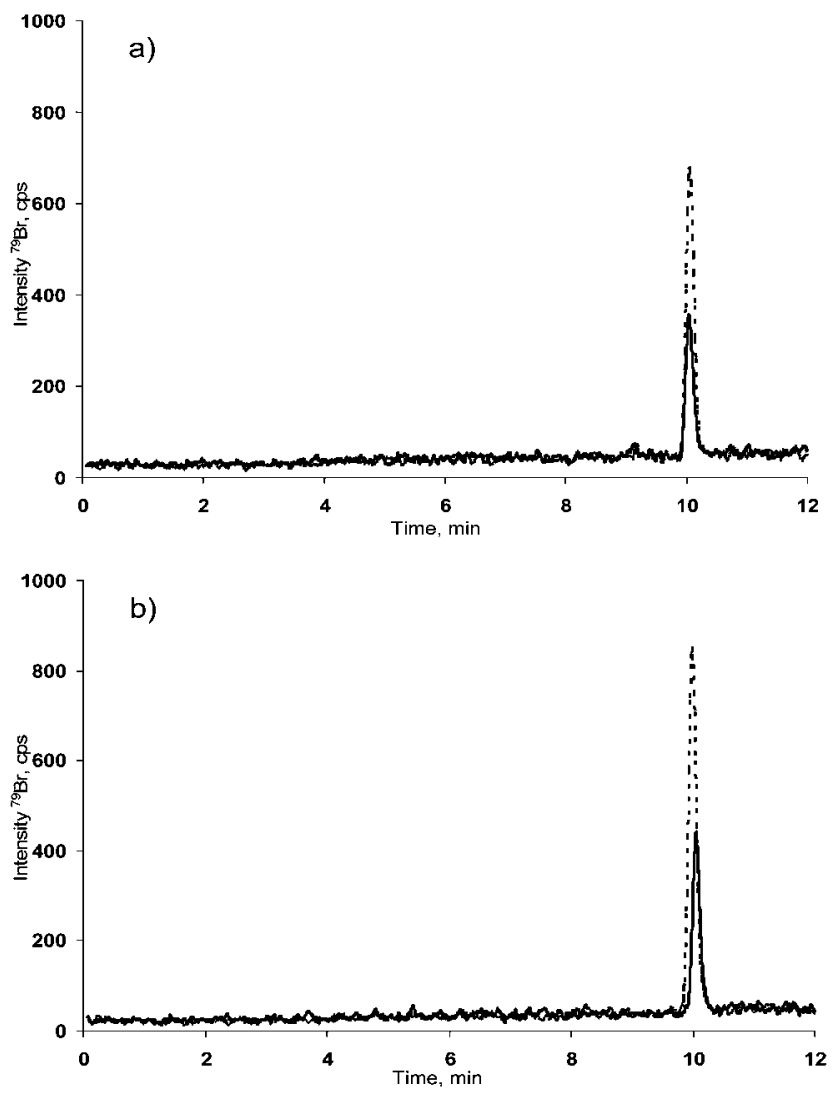

Fig. 3 HPLC-ICP MS chromatograms of (a) liver samples; (b) faeces samples. - sample; --- sample spiked with $0.25 \mu \mathrm{g} \mathrm{mL} \mathrm{m}^{-1}$ of bis(pentabromophenyl) ether. 
$20 \mathrm{ng} \mathrm{mL}^{-1}$ (as Br) and similar for all the compounds taken into account the uncertainty about the exact concentration of the compound in the purchased standards.

The retention times were stable within $1 \%$, the exact values for three injections for the different compounds given in brackets: BDE-47 (0.5\%), BDE-85 (0.40\%), BDE-100 (0.35\%), BDE-138 $(1.15 \%)$, BDE-155 (0.44\%), BDE-201 (0.7\%), BDE-206 (0.9\%), BDE-207 (0.48\%), BDE-208 (0.11\%), and BDE-209 (0.6\%). The average repeatability of the peak height was within $5 \%$, the exact values for the different compounds are given in brackets: BDE$47(3.8 \%)$, BDE-85 (9.9\%), BDE-100 (1.22\%), BDE-138 (7.46\%), BDE-155 (2.41\%), BDE-201 (2.38\%), BDE-206 (7.22\%), BDE-207 (3.6\%), BDE-208 (5.8\%) and BDE-209 (2.6\%).

\section{Quantification of the PBDEs in biological samples}

The method was applied to the probing for the metabolite products of decabromodiphenyl ether (bis(pentabromophenyl) ether, DBE-209) and the quantification of the residual compound. The typical HPLC-ICP MS chromatograms are shown in Fig. 3a and $3 \mathrm{~b}$ for the liver and faeces samples, respectively. They show the absence of metabolites of decabromodiphenyl ether, the latter being the only compound present. It could be quantified by the method of standard additions (3-levels). The concentrations determined (3 independent measurements) were $7.9 \pm 0.2$ and $14.1 \pm 1.1 \mu \mathrm{g} \mathrm{mL}^{-1}$ (as Br) for the extracts of liver and faeces, respectively. The reproducibility of the retention times of the samples were $0.25 \%, 0.17 \%, 0.17 \%$ and $0.04 \%$ for the liver, spiked liver, faeces and spiked faeces samples, respectively. The precision for three independent measurements was $6.8 \%$ and $6.9 \%$ for liver and faeces samples respectively.

The method was validated by demonstrating the agreement of the results obtained with those obtained by HPLC with radioactivity detection described elsewhere: ${ }^{6} 7.8$ and $11.5 \mu \mathrm{g}$ of $\mathrm{Br}$ $\mathrm{mL}^{-1}$ for the extracts of the liver and faeces samples, respectively.

\section{Conclusion}

The use of a novel ICP mass spectrometer equipped with the fast frequency-matching RF generator was demonstrated to allow the introduction of HPLC mobile phases containing up to $90 \%$ of acetonitrile at high flow rates $\left(1.5 \mathrm{~mL} \mathrm{~min}{ }^{-1}\right)$ thus opening new perspectives for applications of HPLC-ICP MS coupling. This performance was the key feature enabling the development of a method for the screening for metabolites of decabromodiphenyl ether (bis(pentabromophenyl) ether) in a rat metabolic study. The HPLC-ICP MS developed offers the accuracy of HPLC with radioactivity detection and is an alternative to other methods for screening PBDE metabolites in biological samples.

\section{Acknowledgements}

The authors thank Ms. Ewelina Dziubakiewicz, ERASMUS exchange student from the Mikolaj Kopernik University in Torun, Poland, for her assistance during this study, and Prof. Ryszard Lobinski (CNRS, Pau) for the critical reading of the manuscript. The financial support of The Conseil Regional d'Aquitaine (2007/303002PFM) and FEDER (31486/08011464) is acknowledged.

\section{Notes and references}

1 M. J. La Guardia, R. C. Hale and E. Harvey, Environ. Sci. Technol., 2006, 40, 6247-6254.

2 L. G. Birnbaum and D. F. Staskal, Environ. Health Perspectives, 2004, 112, 9-17.

3 in Institute for Health and Consumer Protection, Office for Official Publications of the European Communities, Luxembourg, 2002.

4 J. P. Antignac, R. Cariou, D. Zalko, A. Berrebi, J. P. Cravedi, D. Maume, P. Marchand, F. Monteau, A. Riu, F. Andre and B. Le Bizec, Environ. Pollut., 2009, 157, 164-173.

5 C. Naert, M. Piette, N. Bruneel and C. Van Peteghem, Arch. Environ. Contam. Toxicol., 2006, 50, 290-296.

6 A. Riu, J. P. Cravedi, L. Debrauwer, A. Garcia, C. Canlet, I. Jouanin and D. Zalko, Environ. Int., 2008, 34, 318-329.

7 C. P. Rice, S. M. Chernyak, L. Begnoche, R. Quintal and J. Hickey, Chemosphere, 2002, 49, 731-737.

8 R. Cariou, J. P. Antignac, P. Marchand, A. Berrebi, D. Zalko, F. Andre and B. Le Bizec, J. Chromatogr., A, 2005, 1100, 144-152.

9 R. Cariou, J. P. Antignac, D. Zalko, A. Berrebi, J. P. Cravedi, D. Maume, P. Marchand, F. Monteau, A. Riu, F. Andre and B. L. Bizec, Chemosphere, 2008, 73, 1036-1041.

10 A. Covaci, S. Voorspoels, L. Ramos, H. Neels and R. Blust, J. Chromatogr., A, 2007, 1153, 145-171.

11 A. F. Lagalante and T. D. Oswald, Anal. Bioanal. Chem., 2008, 391, 2249-2256.

12 A. Bacaloni, L. Callipo, E. Corradini, P. Giansanti, R. Gubbiotti, R. Samperi and A. LaganÃ, J. Chromatogr., A, 2009, 1216, 64006409 .

13 L. Debrauwer, A. Riu, M. Jouahri, E. Rathahao, I. Jouanin, J. P. Antignac, R. Cariou, B. Le Bizec and D. Zalko, J. Chromatogr., A, 2005, 1082, 98-109.

14 D. Zalko, C. Prouillac, A. Riu, E. Perdu, L. Dolo, I. Jouanin, C. Canlet, L. Debrauwer and J. P. Cravedi, Chemosphere, 2006, 64, 318-327.

15 R. Lobinski, Appl. Spectrosc., 1997, 51, 260A-278A.

16 J. Szpunar, Analyst, 2000, 125, 963-988.

17 L. Bendahl, S. H. Hansen, B. Gammelgaard, S. Sturup and C. Nielsen, J. Pharm. Biomed. Anal., 2006, 40, 648-652.

18 R. S. Houk, Anal. Chem., 1986, 58, 97A-105A.

19 A. P. Vonderheide, M. Montes-Bayon and J. A. Caruso, J. Anal. At. Spectrom., 2002, 17, 1480-1485.

20 D. Proefrock, P. Leonhard, S. Wilburg and A. Prange, J. Anal. At. Spectrom., 2004, 19, 623-631.

21 B. P. Jensen, B. Gammelgaard, S. H. Hansen and J. V. Andersen, J. Anal. At. Spectrom., 2005, 20, 204-209.

22 J. K. Nicholson, J. C. Lindon, G. Scarfe, I. D. Wilson, F. AbouShakra, J. Castro-Perez, A. Eaton and S. Preece, Analyst, 2000, 125, 235-236.

23 D. Schaumloeffel, J. R. Encinar and R. Lobinski, Anal. Chem., 2003, 75, 6837-6842.

24 L. Bendahl, S. Sturup, B. Gammelgaard and S. H. Hansen, J. Anal. At. Spectrom., 2005, 20, 1287-1289.

25 D. Proefrock and A. Prange, J. Chromatogr., A, 2009, 1216, 67066715 . 